To reduce the dynamic loading and prolong the service life of a semi-wagon's girder beam by improving its fatigue strength, it has been proposed to improve its design. A special feature of the girder beam is that its middle part (the distance between the rear supports of auto-couplings) consists of a $U$-shaped profile, covered with a horizontal sheet above which an I-beam is located. Elastic elements are placed between the horizontal part of the $U$-shaped profile's shelf and the sheet. Mathematical modeling was performed to substantiate the proposed technical solution. A mathematical model has been constructed describing the fluctuations of the bouncing wagon. It has been established that the maximum vertical acceleration of the body is about $1.8 \mathrm{~m} / \mathrm{s}^{2}$ $(0.18 \mathrm{~g})$, and of the bogie - about $9.0 \mathrm{~m} / \mathrm{s}^{2}(0.9 \mathrm{~g})$. Based on our calculations, we can conclude that a wagon's movement is assessed as "excellent". In this case, the use of the girder beam with elastic links makes it possible to reduce the dynamic load on a wagon, in comparison with the prototype, by almost $35 \%$.

The main indicators of the strength of the improved load-bearing structure of a wagon have been determined. The maximum equivalent strains occur, in this case, in the upper horizontal sheet of the girder beam, and are 136.0 MPa, which are lower, by $20 \%$, than those of the prototype wagon. The results of the modal analysis of the load-bearing structure of a semi-wagon taking into consideration the improvement measures have demonstrated that their natural frequencies of oscillations are within the permissible limits.

Our research could help reduce the dynamic loading on the load-bearing structures of wagons in operation, as well as design the innovative structures of rolling stock

Keywords: freight wagon, semi-wagon, load-bearing structure, girder beam, dynamic loading, strength, fatigue strength, frequency analysis, transport mechanics, railroad transport

Received date 28.07.2020

Accepted date 08.09.2020

Published date 23.10.2020

1. Introduction

Ensuring the smooth operation of the transport industry is possible with the reliable and coordinated operation of some of its components. It is known that one of the most important ones among such components is railroad transport. At present, achieving the leadership positions of the railroad industry requires the use of innovative rolling stock. Designing such rolling stock should currently employ the principles of multifunctionality and multimateriality. This would improve the technical-economic performance of carriages, as well as increase the efficiency of their operation.

The most frequent damage to load-bearing structures of wagons can be detected from the statistical treatment of operational data. This could make it possible to see the patterns regarding the weakest points and determine the priority directions of scientific research. For example, according to data from JSC "Ukrzaliznytsia”, 194,656 cars were repaired in 2019. The percentage distribution of the most frequent
UDC 629.463.001.63

DOI: $10.15587 / 1729-4061.2020 .211936$

\section{ESTABLISHING PATTERNS IN THE DYNAMIC LOADING ON THE BODY OF A SEMI-WAGON WITH AN ELASTIC MIDDLE PART OF THE GIRDER BEAM}

\author{
O. Fom i n
}

Doctor of Technical Sciences, Professor

Department of Cars and Carriage Facilities

State University of Infrastructure and Technologies

Kyrylivska str., 9, Kyiv, Ukraine, 04071

E-mail: fomin1985@ukr.net

A. Lov sk a

$\mathrm{PhD}$, Associate Professor

Department of Wagons

Ukrainian State University of Railway Transport

Feierbakh sq., 7, Kharkiv, Ukraine, 61050

I. Medvedie v

$\mathrm{PhD}$

Department of Logistics and Traffic Safety

Volodymyr Dahl East Ukrainian National University

Tsentralnyi ave., 59-a, Severodonetsk, Ukraine, 93400

H. Shatkovska

$\mathrm{PhD}$, Associate Professor

Department of Physics

Kyiv National University of Technologies and Design Nemyrovycha-Danchenka str., 2,

Kyiv, Ukraine, 01011

Copyright (C) 2020, O. Fomin, A. Lovska, I. Medvediev, H. Shatkovska This is an open access article under the CC BY license (http://creativecommons.org/licenses/by/4.0)

damage to wagons by nodes is shown in Fig. 1. In this case, the number of damages to the components of the carriages is indicated in parentheses.

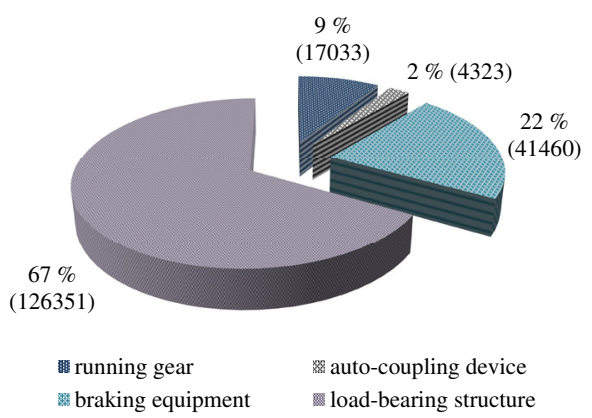

Fig. 1. Distribution of damage by wagon nodes

Thus, the dominating percentage of damage accounts for the load-bearing structures of wagons $-67 \%$. Semi-wagons 
suffer the greatest amount of damage in operation. For the most part, these damages are caused by the effect exerted on the load-bearing structures by significant dynamic loads arising during operation. In particular, the shunting of wagons, loading and unloading operations, railroad and ferry transportation, etc. Cyclical operational loads reduce the fatigue strength of load-bearing structures of wagons in operation and cause the need for unplanned types of repair or exclusion of cars from the inventory fleet. Currently, the renewal of the wagon fleet is negligible. At the same time, there is a significant shortage of rolling stock to ensure the transportation process. Most available rolling stock has already exhausted its rated resource and is being operated taking into consideration the extension of its service life. Such an acute shortage of rolling stock may contribute to the deterioration of the volume of transported goods and, therefore, the economic indicators of this country.

Therefore, it is important to implement new progressive solutions considering the possibility of increasing the fatigue strength of rolling stock and prolonging its service life. This is possible by reducing the dynamic load on the load-bearing structures of wagons, as well as by improving the indicators of fatigue strength. Implementation of these solutions is possible by considering the principles of multifunctionality and multimateriality at the stage of design of the load-bearing structures of wagons at wagon-building enterprises.

\section{Literature review and problem statement}

The strength of the load-bearing structure of a freight wagon with variable use of cargo space was analyzed in work [1]. In order to reduce the fatigue strength of the frame of the wagon and increase cargo space, the authors proposed removing the girder beam of the frame. In this case, the longitudinal load is accepted by the main side beams of the frame, which have an increased intersection.

The static strength of the load-bearing structure of the Zans series wagon is examined in [2]. The calculation was carried out using the CosmosWorks software (France), which implements the method of finite elements. The results obtained could contribute to the construction of the optimal structure of wagons. However, no measures to reduce the dynamic load on the frame of the wagon by applying the principles of the multifunctionality of its elements were proposed by the authors.

An analysis of theoretical and experimental studies of the strength properties of rolling stock elements was reported in [3] using an example of the girder beam of freight wagons. Calculations were performed using a modern package of applications. The presented example of the use of the proposed approach proved its efficiency and effectiveness, as well as the proper area of the relevant research. However, this approach can be implemented in relation to the metallic load-bearing structures of wagons. That is, using it to study the multifunctional and multi-material structures is not appropriate.

The choice of structural solutions for the elements of wagons with a small tare mass is described in [4]. The procedure used was a comparative assessment of strength, endurance, and stability indicators of the load-bearing structure with a minimum mass made from different materials. In this case, the introduction of elastic links in the load-bearing structure of wagons to increase fatigue strength was not proposed by the authors.
The causes of cracks in a load-bearing structure of the frame of a wagon are detected in [5]. The paper describes the methodology used to identify the causes of cracks near a welding joint. The Sgmns type of wagon was used to calculate the frame. However, the authors of the cited paper identified the causes of cracks only; no measures to prevent them in the load-bearing structures by using a multi-material approach were proposed.

The rationale for choosing a new profile for the girder beam of a freight wagon is reported in [6]. The work shows a series of structural solutions of frames for the freight wagons of different types. The authors gave the results of calculating the strength of the load-bearing structures of wagons taking into consideration the proposed solutions. In this case, these solutions imply changing the geometry of the profile of the girder beam. No measures to reduce the dynamic load and fatigue strength of the girder beam were suggested in the work.

The peculiarities of improvement of the design of the frame of a freight wagon are considered in [7]. The calculation of strength was carried out by the method of finite elements, implemented in the Lyra programming environment. The calculation results confirmed the feasibility of the proposed solutions. However, the authors did not investigate the fatigue strength of the wagon and the impact of the proposed solutions on the dynamic load on the wagon.

Measures to reduce the dynamic load on the load-bearing structure of a wagon during combined transportation are given in paper [8]. The authors performed the mathematical modeling and computer simulation of a wagon's dynamic load taking into consideration the proposed measures. The results of the calculation allowed them to conclude that the developed technical solutions contribute to the reduction of the dynamic load of the load-bearing structure of the wagon at combined transportation by $30 \%$ compared to the existing conditions of car operation. It is important to note that these solutions imply improving the scheme of interaction of load-bearing structures of wagons with the means of combined transportation. In this case, the authors did not conduct research into improving the load-bearing structure of the wagon to reduce the dynamic load and fatigue during operation.

Our analysis of the scientific literature allows us to conclude that it is advisable to conduct a study aimed at determining the dynamic load on the body of a semi-wagon with the elastic middle part of the girder beam. This could improve the fatigue strength of the load-bearing structure of the wagon and reduce the amount of damage during operation. In addition, our research would contribute to the construction of fundamentally new resource-saving wagon designs that could improve the efficiency of the railroad transport operation.

\section{The aim and objectives of the study}

The aim of this study is to identify patterns in the dynamic load and strength of the load-bearing structure of a semi-wagon's body with elastic elements in the girder beam.

To accomplish the aim, the following tasks have been set:

- to build a computer model of the load-bearing structure of a semi-wagon with elastic elements in the girder beam;

- to investigate the dynamic load on the load-bearing structure of a semi-wagon with elastic elements in the girder beam; 
- to determine the main indicators of the strength of the load-bearing structure of a semi-wagon with elastic elements in the girder beam.

\section{Construction of a computer model of the load-bearing structure of a semi-wagon with elastic elements in the girder beam}

To reduce the dynamic load, as well as prolong the service life of the load-bearing structure of a semi-wagon, it is necessary to improve the girder beam. It is proposed using, instead of a standard girder beam (Fig. 2,a), a beam with elastic elements. In this case, the girder beam of a semi-wagon has a U-shaped cross-section, covered on the top with the horizontal sheet above which an I-beam is placed (Fig. 2, b).

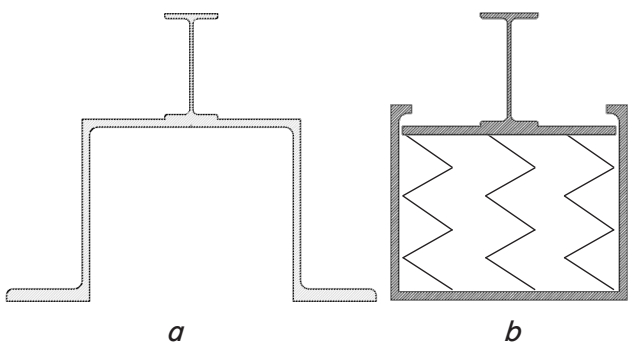

Fig. 2. Cross-section of the girder beam of a semi-wagon: $a$ - standard girder beam; $b$ - girder beam with elastic elements

The load-bearing structure of a semi-wagon with elastic elements in the girder beam is shown in Fig. 3.

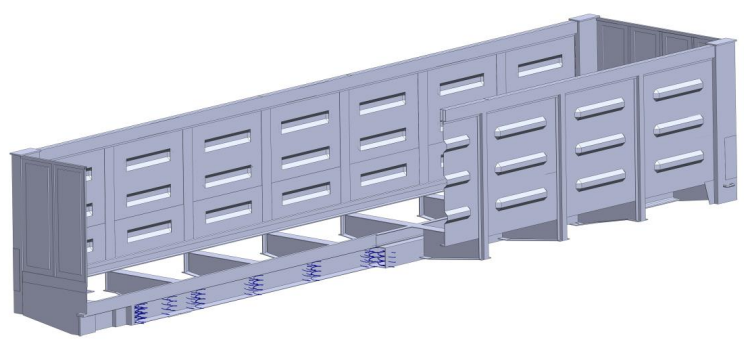

Fig. 3. The load-bearing structure of a semi-wagon with elastic elements in the girder beam

The elastic elements, in this case, are placed in the zone between the rear supports of the auto-coupling devices (Fig. 4). That is, the console parts of the frame are identical to the prototype wagon. This makes it possible to use the standard auto-coupling device SA-3 on a wagon.

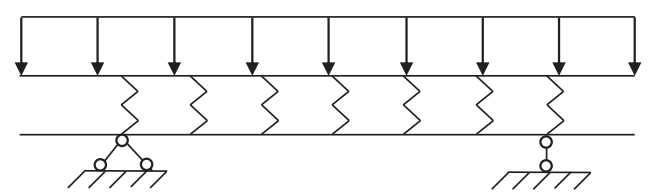

Fig. 4. Schematic action of loads on the girder beam of a semi-wagon

A spatial computer model of the load-bearing structure of a semi-wagon was built in the programming environment SolidWorks (France). The prototype chosen was a semi-wagon, model 12-757, made at PJSC "KVBZ" (Ukraine, Kremenchuk).

\section{Studying the dynamic load on the load-bearing structure of a semi-wagon with elastic elements in the girder beam}

To determine the vertical accelerations of the load-bearing structure of a semi-wagon taking into consideration the proposed measures, we performed mathematical modeling. The study was conducted in the XZ plane. Since the elastic elements that are installed in the girder beam operate under bouncing oscillations, which characterize the translational movements of the wagon relative to the vertical axis, the flat coordinate system was considered. The estimated scheme of a semi-wagon is shown in Fig. 5. When building the equations of the car's movement, it was taken into consideration that it moves along an elastic-viscous track [9]. In this case, it is suggested that the reactions of the track are proportional to both its deformation and the rate of this deformation.

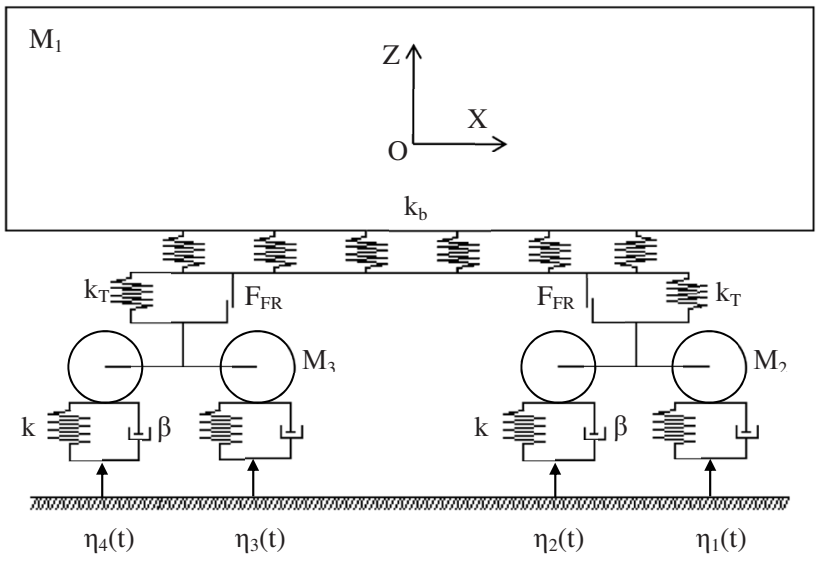

Fig. 5. The estimated scheme of a semi-wagon

The differential equations of the wagon movement take the following form:

$$
\begin{aligned}
& M_{1} \cdot \frac{\mathrm{d}^{2}}{\mathrm{~d} t^{2}} q_{1}+C_{1,1} \cdot q_{1}+C_{1,2} \cdot q_{2}+C_{1,3} \cdot q_{3}= \\
& =-F_{F R} \cdot\left(\operatorname{sign}\left(\frac{\mathrm{d}}{\mathrm{d} t} \delta_{1}\right)+\operatorname{sign}\left(\frac{\mathrm{d}}{\mathrm{d} t} \delta_{2}\right)\right), \\
& M_{2} \cdot \frac{\mathrm{d}^{2}}{\mathrm{~d} t^{2}} q_{2}+C_{2,1} \cdot q_{1}+C_{2,2} \cdot q_{2}+C_{2,3} \cdot q_{3}+B_{2,2} \cdot \frac{\mathrm{d}}{\mathrm{d} t} q_{2}= \\
& =F_{F R} \cdot \operatorname{sign}\left(\frac{\mathrm{d}}{\mathrm{d} t} \delta_{1}\right)+k\left(\eta_{1}+\eta_{2}\right)+\beta\left(\frac{\mathrm{d}}{\mathrm{d} t} \eta_{1}+\frac{\mathrm{d}}{\mathrm{d} t} \eta_{2}\right), \\
& M_{3} \cdot \frac{\mathrm{d}^{2}}{\mathrm{~d} t^{2}} q_{3}+C_{3,1} \cdot q_{1}+C_{3,2} \cdot q_{2}+C_{3,3} \cdot q_{3}+B_{3,3} \cdot \frac{\mathrm{d}}{\mathrm{d} t} q_{3}= \\
& =F_{F R} \cdot \operatorname{sign}\left(\frac{\mathrm{d}}{\mathrm{d} t} \delta_{2}\right)+k\left(\eta_{3}+\eta_{4}\right)+\beta\left(\frac{\mathrm{d}}{\mathrm{d} t} \eta_{3}+\frac{\mathrm{d}}{\mathrm{d} t} \eta_{4}\right),
\end{aligned}
$$

where $M_{i}$ are the inertial coefficients of the elements of an oscillatory system (a car body and two running parts); $C_{i j}$ is the characteristic of the elasticity of the elements of an oscillatory system; $B_{i j}$ is the scattering function; $a$ is the half the base of a bogie; $q_{i}$ are the generalized coordinates corresponding to the translational movement relative to the vertical axis of, respectively, the body of the wagon, the first and the second bogie; $k$ is the rigidity of spring suspension; 
$\beta$ is the damping factor; $F_{F R}$ is the force of absolute friction in a spring kit; $\delta_{i}$ are the deformations of the elastic elements of spring suspension; $\eta(t)$ is the track's irregularities.

The following is accepted in the motion equations (1) to (3):

$-Z_{1} \sim q_{1}$ is the coordinate characterizing the translational movements of the body relative to the vertical axis;

$-Z_{2} \sim q_{2}$ is the coordinate that characterizes the translational movements of the first bogie in the direction of motion relative to the vertical axis;

$-Z_{3} \sim q_{3}$ is the coordinate that characterizes the translational movements of the second bogie in the direction of motion relative to the vertical axis.

The irregularity of the track was described as a periodic function

$$
\eta(t)=\frac{d}{2}(1-\cos \omega t)
$$

where $d$ is the set irregularity depth; $\omega$ is the frequency of oscillations.

In this case, a connection between the body and running gear was described as a consistent elastic link (Fig. 6):

$$
C=\frac{k_{b} \cdot\left(k_{T}+k_{T}\right)}{k_{b}+\left(k_{T}+k_{T}\right)} .
$$

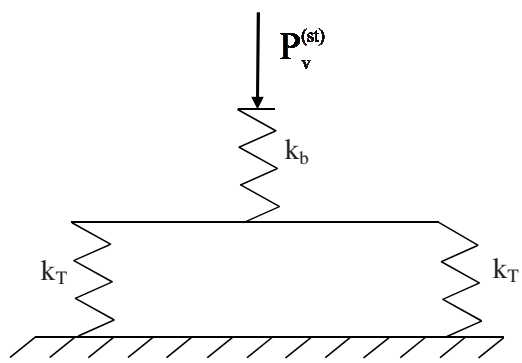

Fig. 6. Schematic of a loading transfer from the body of the wagon with elastic elements in the girder beam on the running gear $P_{v}^{(s t)}$ - vertical static load

The Mathcad software package was used to solve the differential equations of motion [10-12]. In this case, the initial movements and speeds were accepted to equal zero [13-15]. The calculation results are shown in Fig. 7, 8.

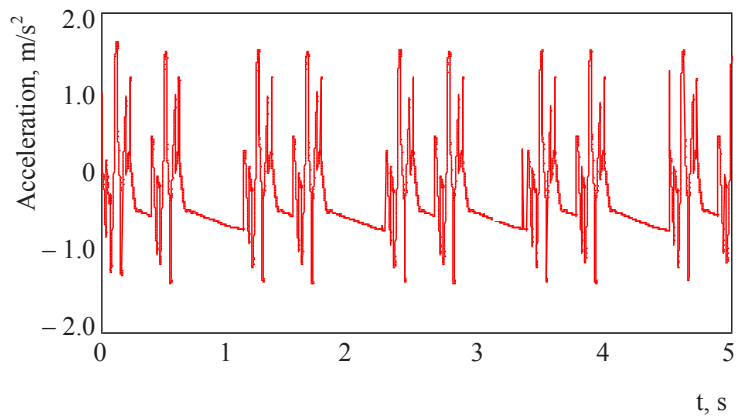

Fig. 7. Acceleration of the body of a semi-wagon in the center of masses

The maximum vertical acceleration of the body in an empty state is about $1.8 \mathrm{~m} / \mathrm{s}^{2}(0.18 \mathrm{~g})$, and of the bogies - are about $9.0 \mathrm{~m} / \mathrm{s}^{2}(0.9 \mathrm{~g})$. Based on our calculations, we can conclude that the wagon's motion is assessed to be "excellent" $[16,17]$. In this case, the use of the girder beam with elastic elements makes it possible to reduce the dynamic load on a wagon, in comparison with the prototype, by almost $35 \%$.

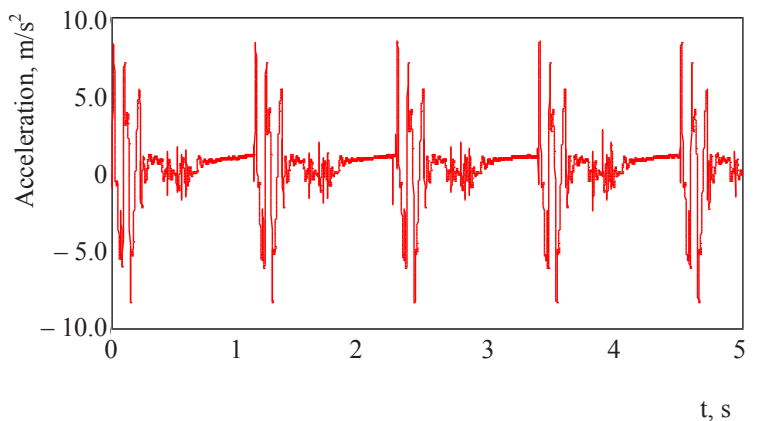

Fig. 8. Acceleration of bogies

\section{Determining the main indicators of the strength of the load-bearing structure of a semi-wagon with elastic elements in the girder beam}

To determine the main indicators of the strength of the load-bearing structure of a semi-wagon with elastic elements in the girder beam, the calculation was performed. It was carried out using a method of finite elements in the SolidWorks Simulation programming environment (CosmosWorks) [18-22]. The finite-element model of the load-bearing structure of a semi-wagon is shown in Fig. 9. Spatial tetrahedra were used as finite elements. To determine the optimal number of the elements, a graphic-analytic method was applied. The method is based on the graphical representation of allowable solutions and the objective function of the problem. The essence of the method in solving a given problem is to build the dependence of the maximum equivalent stresses on the number of finite elements. When this dependence starts to be described as a horizontal line, it is an optimism of the number of finite elements. The number of nodes of the model was 75,031 , elements $-237,913$. The maximum size of the element was $120 \mathrm{~mm}$, and the minimum size $-24 \mathrm{~mm}$. The percentage of the elements with an aspect ratio less than three is 4.9 , exceeding ten -55.1 . The minimum number of the elements in the circle was 9 , the ratio of the increase in the size of the elements was 1.7. A material of the load-bearing structure of a semi-wagon is the steel of grade 09G2S.

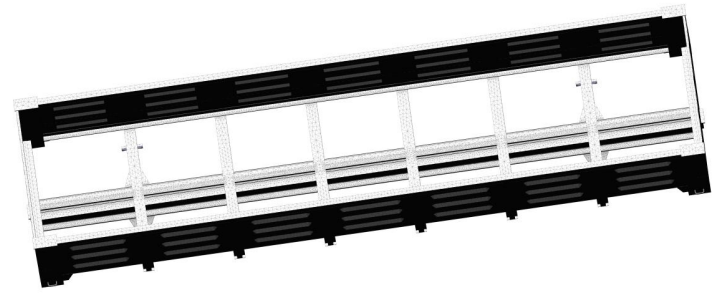

Fig. 9. The finite-element model of the load-bearing structure of a semi-wagon

The estimated scheme of the load-bearing structure of a semi-wagon is shown in Fig. 10.

When building an estimation scheme, it was taken into consideration that the load-bearing structure of a semi-wagon is exposed to the vertical load $P_{\mathrm{v}}^{(\mathrm{st})}$ exerted by the weight of the cargo (coal). It was also taken into consideration that 
the side and end walls are exposed to the thrust effort $P_{t}$. The schematic action of the bulk cargo's thrust efforts on the body of a semi-wagon is shown in Fig. 11 [23]. In this case, the thrust effort on the side walls is governed by the law of a triangle with a maximum at the base. The end walls (doors) are exposed to the thrust effort according to the law of trapeze. The numerical values of the thrust efforts were determined on the basis of the methodology given in [23]. The calculation results are given in Tables 1,2.

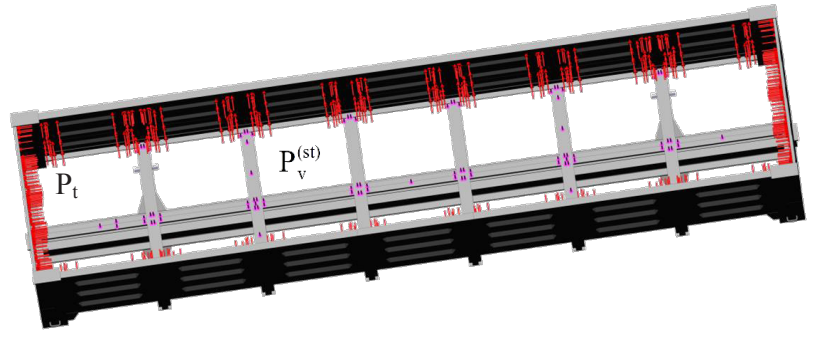

Fig. 10. The estimated scheme of the load-bearing structure of a semi-wagon

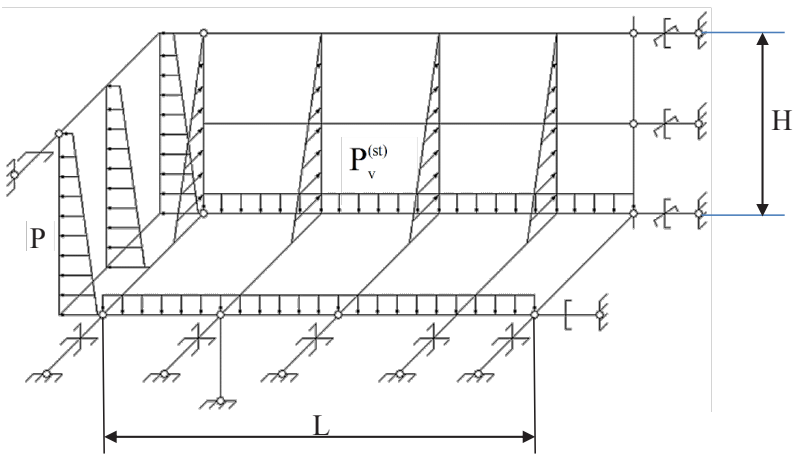

Fig. 11. Schematic action of thrust efforts of bulk cargo on the body of a semi-wagon

In this case, the stiffness of the elastic elements should be in the range from $6,000(\mathrm{kN} / \mathrm{m}) / \mathrm{m}^{2}$ to $8,000(\mathrm{kN} / \mathrm{m}) / \mathrm{m}^{2}$. The model was fixed in the zones when the body rested on the running parts.

Table 1

Numerical value of the bulk cargo pressure on the elements of the side walls of the body of a semi-wagon

\begin{tabular}{|c|c|}
\hline Rack of a side wall & Bulk cargo pressure, $\mathrm{kPa}$ \\
\hline corner & 7.083 \\
\hline first from the console & 13.03 \\
\hline second from the console & 11.895 \\
\hline third from the console & 8.92 \\
\hline
\end{tabular}

Table 2

Numerical value of the bulk cargo pressure on the elements of the end walls of the body of a semi-wagon

\begin{tabular}{|c|c|}
\hline Element of an end door & Bulk cargo pressure, $\mathrm{kPa}$ \\
\hline \multirow{2}{*}{ corner rack } & $50.06^{*}$ \\
& $44.98^{* *}$ \\
\hline \multirow{2}{*}{ intermediate rack } & $100.12^{*}$ \\
& $89.96^{* *}$ \\
\hline \multirow{2}{*}{ middle rack } & $50.06^{*}$ \\
& $44.98^{* *}$ \\
\hline
\end{tabular}

Note: * - pressure on the lower part of the rack; ** - pressure on the top of the rack
The results of calculating the strength of the load-bearing structure of a semi-wagon body are shown in Fig. 12, 13.

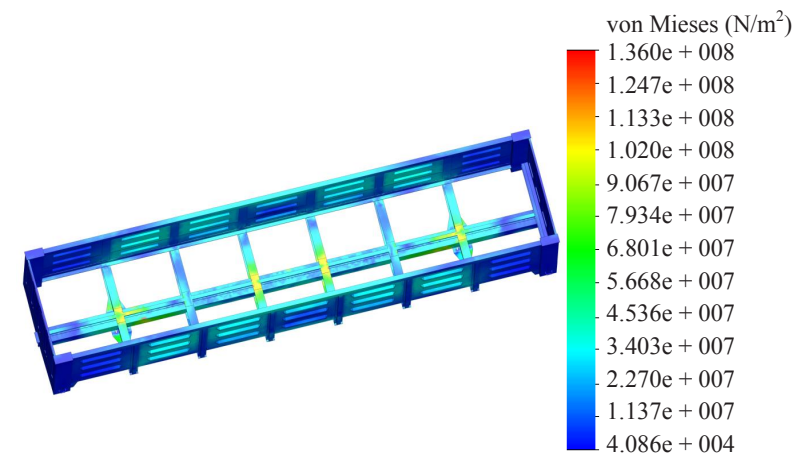

Fig. 12. The stressed state of the load-bearing structure of a semi-wagon

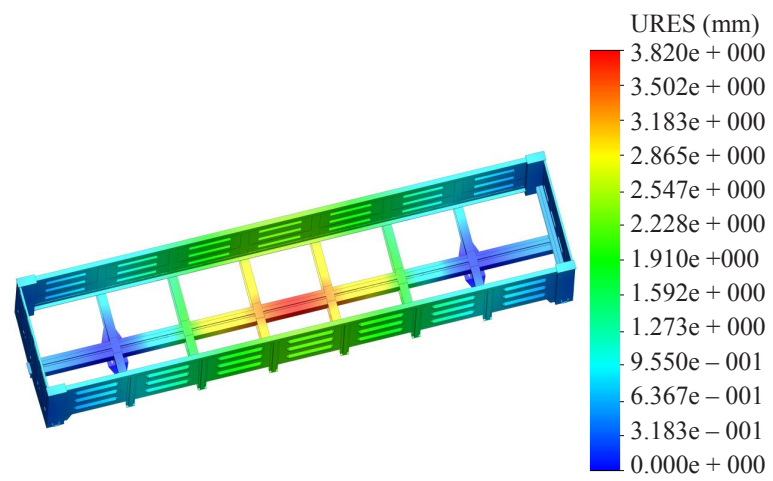

Fig. 13. Displacements in the semi-wagon's load-bearing nodes

The maximum equivalent strains occur, in this case, in the upper horizontal sheet of the girder beam and are equal to $136.0 \mathrm{MPa}$. The maximum displacements occur in the middle part of the girder beam and are equal to $3.8 \mathrm{~mm}$. That is, the strength of the load-bearing structure of a semi-wagon is ensured [16, 17, 24].

Table 3 gives a comparative analysis of the main indicators of the strength of the load-bearing structure of a standard semi-wagon and the improved one.

Table 3

Comparative analysis of the main indicators of the strength of the load-bearing structure of a standard semi-wagon and the improved one

\begin{tabular}{|c|c|c|c|}
\hline Indicator & $\begin{array}{c}\text { Standard } \\
\text { structure }\end{array}$ & $\begin{array}{c}\text { Improved } \\
\text { structure }\end{array}$ & $\begin{array}{c}\text { Discrepancy } \\
\text { percentage }\end{array}$ \\
\hline Stresses, $\mathrm{MPa}$ & 170.0 & 136.0 & 20.0 \\
\hline $\begin{array}{c}\text { Displace- } \\
\text { ments, } \mathrm{mm}\end{array}$ & 4.3 & 3.8 & 12.0 \\
\hline
\end{tabular}

In addition, our study has determined the natural frequencies of the oscillations of the load-bearing structure of the improved semi-wagon. The calculation was performed in the SolidWorks Simulation programming environment (CosmosWorks) using the estimation scheme shown in Fig. 9. The results of the calculation are given in Table 4.

Based on our calculations, we can conclude that the values of the natural frequencies of the oscillations of the 
load-bearing structure of a semi-wagon are within the permissible limits.

Table 4

Numerical values of the natural frequencies of the oscillations of the load-bearing structure of a semi-wagon

\begin{tabular}{|c|c|c|c|}
\hline Mode & Frequency, $\mathrm{Hz}$ & Mode & Frequency, $\mathrm{Hz}$ \\
\hline 1 & 18.311 & 8 & 50.109 \\
\hline 2 & 26.03 & 9 & 59.249 \\
\hline 3 & 30.674 & 10 & 67.005 \\
\hline 4 & 41.701 & 11 & 71.995 \\
\hline 5 & 44.689 & 12 & 72.71 \\
\hline 6 & 46.693 & 13 & 78.045 \\
\hline 7 & 49.274 & 14 & 78.457 \\
\hline
\end{tabular}

To determine the fatigue strength of the load-bearing structure of a semi-wagon, we performed the calculation based on the results from the implemented static analysis. The calculation for fatigue was carried out in the linear form when the accumulation of stresses is diagnosed. The theory of damage accumulation implies that a cycle of the stresses under variable strains above the fatigue limit causes damage. The total damage is equal to the sum of the damages caused by the individual stress cycles. The test base, in this case, was $10^{7}$. We have determined the most damaged element of the load-bearing structure of a semi-wagon, which is the upper horizontal sheet of the girder beam.

At the same time, the fatigue strength of the load-bearing structure of a semi-wagon under the action of cyclic loads is ensured.

It is important to note that the proposed technical solutions could also prove efficient when applied to the long-base structures of wagons.

\section{Discussion of the results of studying the dynamic load on the body of a semi-wagon with an elastic middle part of the girder beam}

Based on the analysis of scientific publications on the research and reduction of the dynamic load on the load-bearing structures of wagons in operation, it has been determined that it is advisable to determine the dynamic load on the body of a semi-wagon with an elastic middle part of the girder beam. Our study would improve the fatigue strength of the load-bearing structure of the wagon and reduce the amount of damage during operation. Given this, a computer model of the load-bearing structure of a semi-wagon with elastic elements in the girder beam was built. All graphic works were carried out in the SolidWorks software package. In this case, the elastic elements are placed between the rear supports of the auto-coupling devices (Fig. 4). This makes it possible to use the standard auto-coupling device SA-3 on a wagon.

The dynamic loading of the load-bearing structure of a semi-wagon with elastic elements in the girder beam has been studied. It was established that the use of the girder beam with elastic elements makes it possible to reduce the dynamic load on the wagon, compared to the prototype, by almost $35 \%$ (Fig. 7 ).

The main indicators of the strength of the load-bearing structure of a semi-wagon with elastic elements in the girder beam have been determined. The calculation was carried out using a method of finite elements in the SolidWorks Simulation software package (CosmosWorks). It was established that the use of elastic elements helps reduce the maximum equivalent stresses in the girder beam (Fig. 12). This is due to the fact that the proposed structure of a girder beam has a closed intersection, as well as a less dynamic load compared to the standard design.

The limitation of this study is that it takes into consideration the bouncing oscillations of a wagon only. It is known that during operation these oscillations are also accompanied by the galloping oscillations caused by a transport delay of track irregularities on the elements of the running parts. Therefore, further research in this area must take such oscillations into consideration.

In addition, an important stage in our study is the implementation of the proposed solutions in the load-bearing structures of long-base wagons. Moreover, the introduction of the elastic elements is possible not only in the girder beam of a semi-wagon. This technical solution can be applied to other components of the load-bearing structure of a body. This could reduce the dynamic load on the components of the load-bearing structure of a wagon and improve the fatigue strength.

\section{Conclusions}

1. A computer model of the load-bearing structure of a semi-wagon with elastic elements in the girder beam has been built. The girder beam has a U-shaped profile, covered on the top with the horizontal sheet above which an I-beam is placed. In this case, the elastic elements are placed in the region between the rear supports of the autocoupling devices. In this case, the console parts of the frame are identical to the prototype wagon. This makes it possible to use the standard auto-coupling device SA-3 on a wagon.

2. The dynamic loading of the load-bearing structure of a semi-wagon with elastic elements in the girder beam has been studied. To this end, a mathematical model was built, describing the translational movements of the wagon in the vertical plane (the oscillations of bouncing). It has been established that the maximum vertical acceleration of the body is about $1.8 \mathrm{~m} / \mathrm{s}^{2}(0.18 \mathrm{~g})$, and of the bogies - about $9.0 \mathrm{~m} / \mathrm{s}^{2}(0.9 \mathrm{~g})$. The wagon motion in accordance with the normative documents is assessed to be "excellent". In this case, the use of the girder beam with elastic elements makes it possible to reduce the dynamic load on the wagon, compared to the prototype, by almost $35 \%$.

3 . The main indicators of the strength of the load-bearing structure of a semi-wagon with elastic elements in the girder beam have been determined. The calculation was carried out using a method of finite elements. The maximum equivalent stresses were registered in the upper horizontal sheet of the girder beam and are 136.0 MPa, which is $20 \%$ lower than that on the prototype wagon. The maximum displacements occur in the middle part of the girder beam and are equal to $3.8 \mathrm{~mm}$. Thus, the 
strength of the load-bearing structure of a semi-wagon is ensured.

We have determined the natural frequencies of the oscillations of the load-bearing structure of a semi-wagon. It is established that the values of the natural oscillation frequency are within the permissible limits.

The results of calculating the fatigue have demonstrated that the load-bearing structure of a semi-wagon withstands the action of cyclic loads with a test base of $10^{7}$ cycles.

Our research could help reduce the dynamic load on the load-bearing structures of wagons during operation, as well as construct the innovative structures of rolling stock.

\section{Acknowledgments}

This study was carried out within the scientific theme of young scientists "Innovative principles of the construction of resource-saving designs of wagons by taking into consideration the refined dynamic loads and functional and adaptive flash concepts", which is funded from the State Budget of Ukraine, 2020.

\section{References}

1. Š̉astniak, P., Kurčík, P., Pavlík, A. (2018). Design of a new railway wagon for intermodal transport with the adaptable loading platform. MATEC Web of Conferences, 235, 00030. doi: https://doi.org/10.1051/matecconf/201823500030

2. Stoilov, V., Purgić, S., Slavchev, S.S. (2015). Static strength analysis of the body of a wagon, series Zans. Journal of The Balkan Tribological Association, 21, 49-57. Available at: https://www.semanticscholar.org/paper/STATIC-STRENGTH-ANALYSISOF-THE-BODY-OF-A-WAGON\%2C-Stoilov-Purgi\%C4\%87/633c5cf68afdd73c979ef9a2c4f505deb600988c

3. Neduzha, L. O., Shvets, A. O. (2018). Theoretical and experimental research of strength properties of spine beam of freight cars. Science and Transport Progress. Bulletin of Dnipropetrovsk National University of Railway Transport, 1 (73), 131-147. doi: https:// doi.org/10.15802/stp2018/123457

4. Boronenko, Y. P., Filippova, I. O. (2017). Selection of constructive solutions of car elements with small empty weight. Science and Transport Progress. Bulletin of Dnipropetrovsk National University of Railway Transport, 3 (69), 121-129. doi https:// doi.org/10.15802/stp2017/104546

5. Milovanović, V., Dunić, V., Rakić, D., Živković, M. (2013). Identification causes of cracking on the underframe of wagon for containers transportation - Fatigue strength assessment of wagon welded joints. Engineering Failure Analysis, 31, 118-131. doi: https:// doi.org/10.1016/j.engfailanal.2013.01.039

6. Sokolov, A. M., Savushkina, I. V., Novoselov, A. Iu., Korotkov, D. S. (2019). Multifunctional configuration for wagon longitudinal tie rod. Transport Rossiyskoy Federatsii. Zhurnal o nauke, praktike, ekonomike, 1 (80), 50-55. Available at: https://cyberleninka. ru/article/n/universalnyy-profil-dlya-hrebtovoy-balki-vagonov

7. Vatulia, G., Falendysh, A., Orel, Y., Pavliuchenkov, M. (2017). Structural Improvements in a Tank Wagon with Modern Software Packages. Procedia Engineering, 187, 301-307. doi: https://doi.org/10.1016/j.proeng.2017.04.379

8. Fomin, O., Lovska, A., Kulbovskyi, I., Holub, H., Kozarchuk, I., Kharuta, V. (2019). Determining the dynamic loading on a semi-wagon when fixing it with a viscous coupling to a ferry deck. Eastern-European Journal of Enterprise Technologies, 2 (7 (98)), 6-12. doi: https://doi.org/10.15587/1729-4061.2019.160456

9. Domin, Yu. V., Cherniak, H. Yu. (2003). Osnovy dynamiky vahoniv. Kyiv: KUETT, 269.

10. Kir'yanov, D. V. (2006). Mathcad 13. Sankt-Peterburg: BHV. Peterburg, 608.

11. D'yakonov, V. (2000). MATHCAD 8/2000: spetsial'niy spravochnik. Sankt-Peterburg: Piter, 592.

12. Fomin, O., Lovska, A., Pistek, V., Kucera, P. (2020). Research of stability of containers in the combined trains during transportation by railroad ferry. MM Science Journal, 2020 (1), 3728-3733. doi: https://doi.org/10.17973/mmsj.2020_03_2019043

13. Fomin, O. V. (2015). Increase of the freight wagons ideality degree and prognostication of their evolution stages. Scientific Bulletin of National Mining University, 3, 68-76. Available at: http://nv.nmu.org.ua/index.php/en/monographs-and-innovations/ monographs/1078-engcat/archive/2015/contents-no-3-2015/geotechnical-and-mining-mechanical-engineering-machine-building/3040-increase-of-the-freight-wagons-ideality-degree-and-prognostication-of-their-evolution-stages

14. Lovskaya A., Ryibin A. (2016). The study of dynamic load on a wagon-platform at a shunting collision. Eastern-European Journal of Enterprise Technologies, 3 (7 (81)), 4-8. doi: https://doi.org/10.15587/1729-4061.2016.72054

15. Kondratiev, A. V., Gaidachuk, V. E., Kharchenko, M. E. (2019). Relationships Between the Ultimate Strengths of Polymer Composites in Static Bending, Compression, and Tension. Mechanics of Composite Materials, 55 (2), 259-266. doi: https:// doi.org/10.1007/s11029-019-09808-x

16. DSTU 7598:2014. Freight wagons. General reguirements to calculation and designing of the new and modernized $1520 \mathrm{~mm}$ gauge wagons (non-self-propelled) (2015). Kyiv, 162.

17. GOST 33211-2014. Freight wagons. Requirements to structural strength and dynamic qualities (2016). Moscow, 54.

18. Alyamovskiy, A. A. (2007). SolidWorks/COSMOSWorks 2006-2007. Inzhenerniy analiz metodom konechnyh elementov. Moscow, 784.

19. Lovska, A., Fomin, O., Píštěk, V., Kučera, P. (2019). Dynamic load computational modelling of containers placed on a flat wagon at railroad ferry transportation. Vibroengineering PROCEDIA, 29, 118-123. doi: https://doi.org/10.21595/vp.2019.21132

20. Fomin, O., Lovska, A., Radkevych, V., Horban, A., Skliarenko, I., Gurenkova, O. (2019). The dynamic loading analysis of containers placed on a flat wagon during shunting collisions. ARPN Journal of Engineering and Applied Sciences, 14 (21), 3747-3752. Available at: http://www.arpnjournals.org/jeas/research_papers/rp_2019/jeas_1119_7989.pdf 
21. Kliuiev, S. (2018). Experimental study of the method of locomotive wheelrail angle of attack control using acoustic emission. Eastern-European Journal of Enterprise Technologies, 2 (9 (92)), 69-75. doi: https://doi.org/10.15587/1729-4061.2018.122131

22. Kitov, Y., Verevicheva, M., Vatulia, G., Orel, Y., Deryzemlia, S. (2017). Design solutions for structures with optimal internal stress distribution. MATEC Web of Conferences, 133, 03001. doi: https://doi.org/10.1051/matecconf/201713303001

23. Lukin, V. V., Shadur, L. A., Koturanov, V. I., Hohlov, A. A., Anisimov, P. S. (2000). Konstruirovanie i raschet vagonov. Moscow: UMK MPS Rossii, 731.

24. EN 12663-2:2010. Railway applications - structural requirements of railway vehicle bodies - Part 2: Freight wagons.

\begin{abstract}
This paper reports a study into the distribution capacity of a flexible plate in different cross-sections exposed to the external vertical concentrated forces applied in any place of its area. A plate with one pinched side and a series of racks arranged at any distance from the pinching has been considered. In terms of the theory of elasticity and mathematics, solving this problem poses significant difficulties. This has study found that a lateral distribution coefficient could be used to simplify calculations aimed at determining the stressed-strained state of the system. In determining the stressedstrained state of the plate, the calculation method described in work [1] was applied. The plate is cut into a series of longitudinal strips that represent, from the standpoint of construction mechanics, a console strip with one pinched end and resting on a stationary support located at any distance from the pinching. It has been revealed that the distribution capacity of the examined plate in the same cross-section depends insignificantly on the point of application of the concentrated load along the length of the longitudinal strip (between 2.6 and $6.7 \%$ ). The distribution capacity in different cross-sections does differ greatly (in the range of 10 to $30 \%$ ). The result of this study is the proposed unified and easy-to-implement method of calculating plates under any conditions for their resting on supports and when exposed to any external loads. There is also no difficulty in calculating the plates backed by edges in both directions. Other estimation methods in these cases require a different mathematical approach, and, for the case of a series of external loads, or under difficult plate rest conditions, the issue relating to the stressedstrained state of the system remains open

Keywords: longitudinal strip, transverse strip, fictitious pinching, system of equation, lateral distribution coefficient
\end{abstract}

Received date 03.09.2020

Accepted date 07.10.2020

Published date 23.10.2020
UDC 624.21

DOI: $10.15587 / 1729-4061.2020 .213776$

PATTERNS IN THE DISTRIBUTION CAPACITY OF THIN PLATES UNDER DIFFERENT CONDITION FOR THEIR RESTING ON SUPPORTS

\author{
V. Kozhusko \\ Doctor of Technical Sciences, Professor* \\ E-mail: kmksm@ukr.net \\ S. Krasnov \\ $\mathrm{PhD}$, Associate Professor* \\ E-mail: krasnov56@ukr.net \\ K. Berezh n a \\ $\mathrm{PhD}$, Associate Professor* \\ E-mail: beregna@gmail.com \\ S. Ok s a k \\ $\mathrm{PhD}$, Associate Professor \\ Department of Technologies of \\ Road-Building Materials and Chemistry** \\ E-mail:sv.oksak@gmail.com \\ R. S moly a n y u k \\ $\mathrm{PhD}$, Associate Professor \\ Department of Automobile Road Construction \\ and Maintenance ${ }^{\star *}$ \\ E-mail: rovlsm@yahoo.com \\ **Kharkov National Automobile and Highway University \\ Yaroslava Mudroho str., 25, Kharkiv, Ukraine, 61002
} *Department of Bridges, Structures and Building Mechanics**

Copyright (C) 2020, V. Kozhusko, S. Krasnov, K. Berezhna, S. Oksak, R. Smolyanyuk This is an open access article under the CC BY license (http://creativecommons.org/licenses/by/4.0)

\section{Introduction}

The calculation of plates with the considered conditions for resting the sides poses significant difficulties in terms of solving the problems within the theory of elasticity, as well as in mathematical terms. The methods developed for calculating thin plates with different boundary conditions are based on a different approach in terms of the theory of elasticity and mathematics. The resulting solutions are mathematically very complex, so, for plates with different boundary conditions, it is necessary to devise a separate calculation program. This task is even more complicated when loading plates not all over their entire area, that is, when loading with concentrated forces or moments, piecewise evenly distributed loads. If the intensity of distributed loads is not linear, the problem in some cases cannot be solved at 